\title{
THE IMPORTANCE OF PARENTS' EDUCATION IN THE MORPHOFUNCTIONAL DEVELOPMENT OF ADOLESCENT BOYS FROM THE LUBLIN REGION
}

\author{
Education and morphofunctional development
}

HELENA POPŁAWSKA, AGNIESZKA DMITRUK, WOJCIECH HOŁUB

\author{
The Josef Pilsudski University of Physical Education in Warsaw, Faculty of Physical Education and Sport \\ in Biała Podlaska, Department of Human Biological Development
}

Mailing address: Helena Popławska, Faculty of Physical Education and Sport, 2 Akademicka Street, 21-500 Biała Podlaska, tel.: +48 83 3428738, fax: +48 83 3428800, e-mail: helena.poplawska@awf-bp.edu.pl

\begin{abstract}
Introduction. Given the unfavorable economic conditions prevailing in Poland at the turn of the century (system transformation), it seemed advisable to investigate whether parents' education, generally associated positively with the economic situation of the family, still plays an important role in somatic and motor development of their children. Material and methods. The study involved 715 boys, aged 10, 14 and 18, born in the years 1988-1996 and coming from one of the least economically developed region of the country (Lubelskie Vivodeship). Because of parents' education, respondents were divided into two groups: born in families with higher (A) and lower (B) education. Somatic development was assessed based on measurements of height, weight and BMI, and physical fitness on the basis of Eurofit test. Arithmetic means of the somatic and fitness features was normalized according to the arithmetic means and SD of the whole material. Results. Group A was characterized by higher values of the somatic parameters and lower values of motor parameters as compared to group B. Standardization of the results showed that the larger deviation from the average value for the whole material in most somatic and certain fitness features occurred in group B. Conclusions. Despite the unfavorable economic conditions, in which surveyed boys were born and grew up, there was a positive relationship between education of parents and somatic development. This dependency was not observed in the case study of the impact of education of parents on the physical fitness of boys.
\end{abstract}

Key words: teenagers, conditional abilities, coordination abilities, flexibility, economic conditions

\section{Introduction}

At the end of the twentieth century, fitness and physical efficiency of children and adolescents in Poland has deteriorated [1, 2]. Reduction of the level of physical fitness is due to the changing lifestyles of children and youth, manifested, among others, by escalation of physical inactivity phenomenon. In particular, it is clearly evident at the pubescence age [3, 4]. On the basis of CSO survey [5] it was found that a child spends an average of 2.5 hours per day in front of a television or computer. The research also shows that only $30 \%$ of primary school pupils attend extracurricular forms of recreational activities. Physical activity of young people aged 15 and over increases slightly. Half of young people aged 15-19 perform recreational physical activity for at least one hour per week [5].

The morphofunctional development of a young person is affected by several factors of the biogeographical, sociocultural, and economic nature. None of these factors directly affects the physical development, nor any other biological characteristic of humans. Each of them has an impact on certain elements of life and it is only these that impinge on the organism [6]. For example, socio-economic situation of the family is mostly defined in Polish studies on the basis of two variables: parents' education and number of children in the family. The variable "parents' education" also encompasses a synthetic review of domestic conditions in which the child resides: economic, cultural, including hygiene and education. Parents with higher educational status and greater educational awareness, despite the bad economic conditions, can create more favorable conditions for comprehensive development of their offspring, including undertaking physical activity, which is a necessary condition for the proper physical and motor development [1].

Taking into consideration the unfavorable economic conditions prevailing in Poland at the turn of the century (system transformation), it seemed advisable to investigate whether parents' education, generally associated positively with the economic situation of the family, still plays an important role in somatic and motor development of their children.

\section{Material and methods}

The study was conducted in 2005-2007. It involved 715 boys, aged 10, 14 and 18 years old, coming from one of the 
least economically developed region of the country (Lubelskie Voivodeship). The study covered schools selected from both urban and rural areas, where parental consent was obtained to carry out the survey, and there were conditions for the implementation of the planned measurements. Data on date of birth of the child and parents' education were provided by the form master of the researched student.

Somatic development of the subjects was assessed on the basis of measurements of height, weight and BMI. Fitness was determined using selected attempts of the Eurofit test [7]. These were the following tests: the long jump from a spot (explosive power), hand grip (static strength), hanging with bent arms (functional strength), sitting ups (trunk strength), shuttle run $10 \times 5 \mathrm{~m}$ (agility), plate tapping (speed of the upper limb movements - tapping), sit and reach (flexibility), balanced position on one leg (balance). Carrying out these tests allowed to assess conditional abilities (static strength, explosive power, trunk strength, functional strength, agility run) and coordination abilities (tapping, balance) and the flexibility of subjects [8]. Evaluation of physical fitness was carried out in selected schools' sports facilities, as part of physical education classes.

\section{Statistical analysis}

On the basis of education of father and mother, two groups were separated from each age group studied: group A - children whose parents held university degree or higher and middle education, and B - children whose parents held primary education or basic and vocational education. Children from families in which both parents had secondary or vocational school education were not included in this study. The number of respondents in each group based on the parents' education has been presented in Table 1 . Within the separated groups arithmetic means and SD were calculated for the somatic features and motor tests. The significance of differences between groups was assessed by $\mathrm{t}$-Student test for independent observation. Moreover, arithmetic and motor somatic features of groups A and B were standardized to the arithmetic means and SD of all the material in a given age group. Using a single-factor analysis of variance (ANOVA) with application of Newman-Keuls test, the significance of differences between group $\mathrm{A}$ and all the material and the group $B$ and all the material was determined.

Table 1. Number of surveyed boys in age groups analyzed

\begin{tabular}{|c|c|c|c|}
\hline Age in years & Group A & Group B & Total \\
\hline 10 & 133 & 43 & 244 \\
\hline 14 & 140 & 64 & 302 \\
\hline 18 & 102 & 30 & 169 \\
\hline Total & 375 & 137 & 715 \\
\hline
\end{tabular}

group A - higher education

group B - lower education

\section{Results}

Boys of group A were generally characterized by higher height and weight and BMI. The exception was the height of the body of 18-year-olds, and BMI in the group of 14-year-olds, where higher levels of these indicators were observed in group B (Tab. 2). Standardization of the results on the arithmetic means and SD for the whole material showed that the height and weight and BMI of boys in group A were on a similar level compared to all respondents, while greater differences, mostly negative, occurred in group B (Fig. 1).

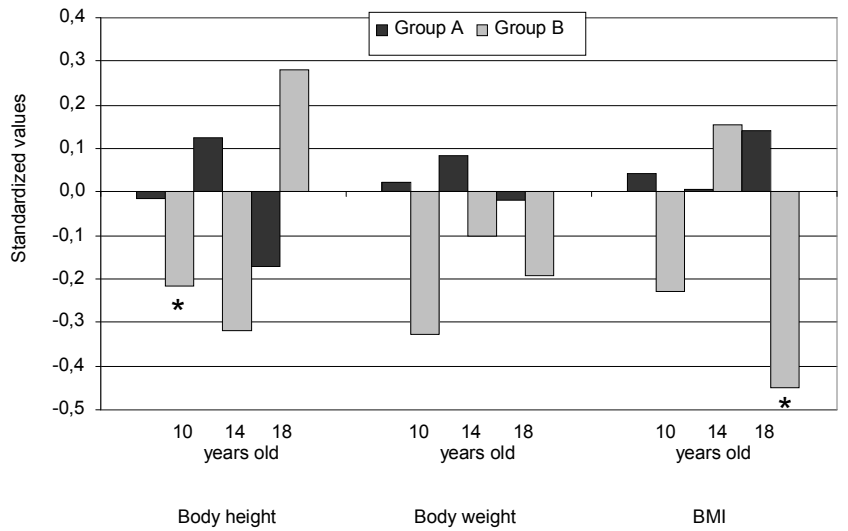

* statistically significant differences at the level $p<0.05$

Figure 1. Standardized values of somatic features in boys depending on parents' education

Analysis of differences in the conditional abilities indicated a higher level in group B. Only in the group of 18year-olds a reverse pattern of results was observed in the case of a static strength and agility running. Significant differences between groups were observed mainly in 10 and 14-year-olds in the trunk strength, functional strength and agility running (Tab. 2). Referring the results to the means for all respondents in the age groups, it can be seen that the boys from group A were characterized by lower levels of these motor abilities than the average for all respondents, with the exception of the static strength for the 18-year-olds. However, comparing the performance of boys in group B to the whole of the material, it turned out that in case of the trunk strength and functional strength and agility run (except the 18-year-olds), the group has obtained better results. The explosive power results of the group were similar to the arithmetic means of the total material, in the case of a static strength no clear trends were identified (Fig. 2). 
Table 2. Level of analyzed somatic features and motor abilities of boys from extreme educational groups of parents

\begin{tabular}{|c|c|c|c|c|c|c|c|c|c|}
\hline \multirow{3}{*}{ somatic features and motor abilities } & \multicolumn{3}{|c|}{10 years } & \multicolumn{3}{|c|}{14 years } & \multicolumn{3}{|c|}{18 years } \\
\hline & \multirow{2}{*}{$\frac{\text { Group A }}{\text { mean } \pm \text { SD }}$} & \multirow{2}{*}{$\frac{\text { Group B }}{\text { mean } \pm S D}$} & \multirow{2}{*}{$\begin{array}{l}\text { T-Student test } \\
\text { value }\end{array}$} & Group A & Group B & \multirow{2}{*}{$\begin{array}{c}\text { T-Student test } \\
\text { value }\end{array}$} & Group A & Group B & \multirow{2}{*}{$\begin{array}{l}\text { T-Student tes } \\
\text { value }\end{array}$} \\
\hline & & & & mean $\pm S D$ & mean $\pm \mathrm{SD}$ & & mean $\pm S D$ & mean $\pm S D$ & \\
\hline Body height & $141.81 \pm 8.05$ & $140.29 \pm 6.78$ & -1.22 & $167.44 \pm 7.96$ & $163.83 \pm 8.35$ & $-2.92^{\star *}$ & $175.83 \pm 8.45$ & $179.43 \pm 6.58$ & $2.46^{*}$ \\
\hline Body weight & $35.75 \pm 6.39$ & $33.61 \pm 4.81$ & $-2.21^{*}$ & $57.99 \pm 8.02$ & $56.43 \pm 7.80$ & -1.32 & $71.59 \pm 6.46$ & $70.30 \pm 9.54$ & -0.69 \\
\hline BMI & $17.81 \pm 2.91$ & $17.06 \pm 1.62$ & $-2.02^{*}$ & $20.67 \pm 2.34$ & $21.03 \pm 2.54$ & 0.97 & $23.25 \pm 2.57$ & $21.76 \pm 2.16$ & $-3.17^{\star \star}$ \\
\hline Static strength & $15.07 \pm 3.21$ & $16.25 \pm 5.38$ & 0.73 & $33.11 \pm 7.52$ & $39.29 \pm 23.98$ & 1.32 & $39.45 \pm 10.45$ & $34.82 \pm 9.11$ & -1.82 \\
\hline Explosive power & $136.33 \pm 22.06$ & $139.88 \pm 21.27$ & 0.92 & $182.88 \pm 22.13$ & $185.52 \pm 22.30$ & 0.79 & $203.29 \pm 27.54$ & $208.70 \pm 44.11$ & 0.64 \\
\hline Trunk strength & $15.98 \pm 4.00$ & $19.05 \pm 6.00$ & $3.10^{* *}$ & $24.65 \pm 4.02$ & $26.05 \pm 4.12$ & $2.27^{*}$ & $22.75 \pm 4.94$ & $25.13 \pm 6.64$ & 1.82 \\
\hline Functional strength & $7.69 \pm 4.91$ & $13.46 \pm 12.28$ & $3.00^{* *}$ & $20.26 \pm 14.22$ & $25.43 \pm 18.00$ & $2.04^{*}$ & $18.02 \pm 18.02$ & $28.32 \pm 14.55$ & $-2.69^{* *}$ \\
\hline Agility run & $22.74 \pm 2.36$ & $21.93 \pm 2.09$ & $-2.13^{*}$ & $20.75 \pm 2.29$ & $19.97 \pm 2.76$ & $-1.96^{*}$ & $19.40 \pm 2.53$ & $20.16 \pm 1.76$ & 1.85 \\
\hline Tapping & $18.18 \pm 3.84$ & $17.61 \pm 3.46$ & -0.90 & $13.08 \pm 4.88$ & $12.12 \pm 2.35$ & -1.89 & $11.15 \pm 4.20$ & $10.15 \pm 1.94$ & -1.80 \\
\hline Balance & $1.63 \pm 0.91$ & $1.25 \pm 0.59$ & $-3.05^{\star \star}$ & $1.35 \pm 0.59$ & $1.18 \pm 0.50$ & $-2.09^{*}$ & $1.35 \pm 0.99$ & $2.37 \pm 2.77$ & $1.98^{*}$ \\
\hline Flexibility & $16.18 \pm 3.59$ & $16.95 \pm 3.83$ & 1.16 & $21.53 \pm 5.88$ & $23.18 \pm 13.82$ & 0.93 & $20.96 \pm 6.87$ & $20.21 \pm 7.32$ & -0.50 \\
\hline
\end{tabular}

group $\mathrm{A}$ - higher education

group B - lower education

* - statistically significant differences at the level $p<0.05$

** - statistically significant differences at the level $\mathrm{p}<0.01$

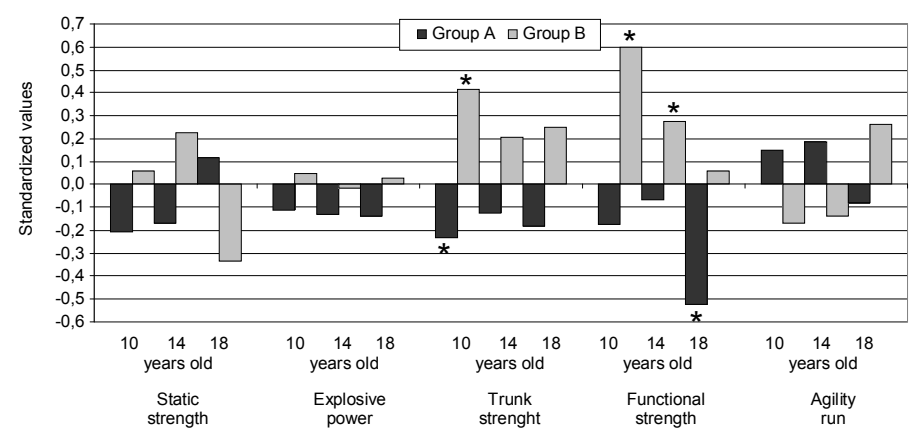

*statistically significant differences at the level $\mathrm{p}<0.05$

Figure 2. Standardized values of fitness abilities in boys depending on parents' education

Analysis of the coordination ability observed on the basis of the rate of upper limb movements (tapping) and the balance showed that better results (lower average values), similarly as in conditional abilities, were achieved by group B. Only the results of balance tests in the 18-yearolds differed from that principle. In this test in each questioned age category the differences between group A and B were statistically significant (Tab. 2). The values of normalized coordination abilities showed that in the case of 10 and 14-year-olds the results of respondents from group A were lower, and higher in group B as referred to the whole

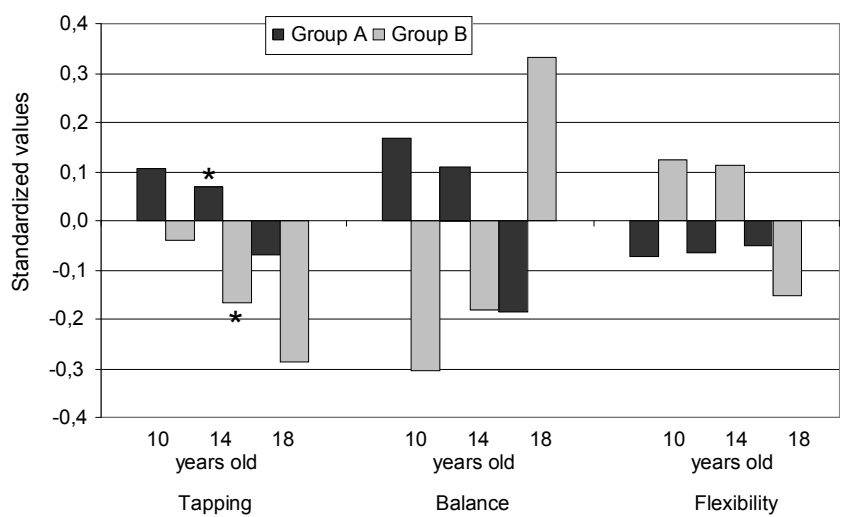

* statistically significant differences at the level $p<0.05$

Figure 3. Standardized values of coordination abilities and flexibility in boys depending on parents' education

material. However, in 18-year-olds there was no such trend (Fig. 3). In the flexibility test the differences between group A and B were not statistically significant (Tab. 2). Greater differentiation in the level of motor ability in relation to the average of the whole material was observed in boys of group B (Fig. 3).

\section{Discussion}

The research of Kozakiewicz et al. [9] shows that the level of education of the inhabitants of the Lublin region does not differ significantly from the education level of the 
entire Polish population, while income per family member was lower than the average nationwide. These data suggest that the parents' higher education is not always synonymous with high wages. Factor of parents' education is extremely complex, it has a multidimensional structure and meaning. It decides, among others, on diet, affects the health prevention, expenditure patterns, preferred methods of upbringing, or ways of spending leisure time [10].

The results indicate the existence of a relation between physical development, and membership in a particular educational group of respondents. The boys in group A were characterized by a higher height, body weight and BMI as compared with the control group B, which is consistent with studies conducted by other authors. For example, Bodzsar [11] studying the Hungarian children aged 7, 10 and 13 years found that subjects whose fathers and mothers had higher education were characterized by the highest body mass, lean body mass and body fat content as compared to other subjects. Similar observations were presented by Eiben and Mascie-Taylor [12] on the basis of studies conducted in Hungary as well. The stronger influence of mother's education than the father's was also found. Also Rożnowski et al. [13], studying the physical development of children and young people from rural areas in Pomerania, noted that in most of the somatic features, with the exception of arm circumference, fatty skin-fold thickness on the belly, BMI and chest circumference, the differences between the groups separated depending on parents' education were significantly higher in favor of children whose parents had higher education. Effect of mother's education was the highest in the age groups from 9 to 13 years, and much more prominently in the mother - son relationship. Datar et al. [14] noted the positive impact of mother's higher education in the BMI of children. BMI increased with an increase in the educational status of fathers and mothers was observed by Resiak [15]. ZadarkoDomaradzka and Tlałka [16] found a clear positive impact of both education of father and mother on height and weight of children of Podkarpacie and Podbeskidzie, and the stronger effect on these parameters in boys had the mother's education than the father. A positive correlation between the somatic indices and education Westephal [17] explains by the higher level of knowledge and awareness of parents, which improves the quality of life of families through a more rational management of the budget. Recently there are also works showing a systematic decrease in the differences between somatic features of children coming from families with different educational status [18, 19].

Previous research on relation of social stratification of parents with the level of physical fitness of children do not give a definite answer to the question about the existing relationship. Research carried out among 13 and 16-yearold children from Poznan showed that parents' education was one of the important factors determining the level of physical fitness of subjects. It turned out that among the 13- year-old boys, most of the results above average were obtained by respondents with mother's secondary and father's higher education. But in the group of 16-year-old boys basic education of father and mother had the biggest influence on obtaining better results in selected fitness tests [20]. Based on national surveys, Przewęda and Dobosz [1] found that in agility-speed and endurance tests, boys from families with highly educated parents were the fittest, and the least fitted were the boys from families with primary education. In performance tests that require strength, there were no clear correlation between the results obtained, and the education level of parents. Szklarska [21] showed that children and adolescents whose parents have higher education were more efficient than children whose parents have primary education. The observed phenomenon related to the boys in the city, in the country-side these relations were very weak or did not occur at all. No clear relationship between parents' education and overall physical fitness of boys was seen by Cieśla and Nowak-Starz [22] and Jaworski and Szopa [23]. Some authors have demonstrated the higher conditional and coordination abilities in groups of children and adolescents of lower social status [10]. According to Malina [24], characteristic for lower socio-economic groups relaxed educational atmosphere allows for children's larger physical activity, which positively affects the development of their physical fitness. The studies confirm the trend outlined above. The boys from the Lublin region in the age of 10 and 14 years from families with lower educated parents were characterized by higher levels of the analyzed motor features. This difference was not seen in 18year-old boys. Perhaps this is due to the fact that at this age there is less parental influence on the lifestyle of their children. Although education is only one factor shaping the individual's worldview, Bronikowski [20] believes that the neglect of education during the school stage can have serious consequences, which may manifest in decreased performance level in adulthood. Drivers of motor skills should be sought in the sphere of consciousness and development of internal motivation.

\section{Conclusions}

1. In the case of adverse economic conditions, in which the surveyed boys grew up, parents' education continue to differentiate their physical development, i.e. the boys from the group of highly educated parents were characterized by a higher height, body weight and BMI.

2. In the case of physical fitness, the dependence observed was not as pronounced in 18-year-old boys.

\section{Literature}

1. Przewęda, R. \& Dobosz J. (2003). Physical condition of Polish youth. Warsaw: Studia i Monografie AWF Warszawa, 98. [in Polish] 
2. Przewęda, R. \& Trześniowski R. (1996). Physical condition of Polish youth in view of research of 1989. Warsaw: Studia i Monografie AWF Warszawa. [in Polish]

3. Brodersen, N.H., Steptoe A., Boniface D.R. \& Wardle J. (2007). Trends in physical activity and sedentary behaviour in adolescence: ethnic and socioeconomic differences. Br. J. Sports Med. 41(3), 140-144.

4. Charzewska, J., Wajszczyk B., Chabros E. \& RogalskaNiedźwiedź M. (2006). Physical activity in Poland in different groups according to age and gender. In $\mathrm{M}$. Jarosz (Ed.) Obesity, nutrition, physical activity, health of the Poles. Warsaw: Instytut Żywności i Żywienia. [in Polish]

5. CSO - Central Statistical Office. (2006). Health Condition of Polish Population in 2004. Warsaw. [in Polish]

6. Bielicki, T., Szklarska A., Kozieł S. \& Welon Z. (2003). System transformation in Poland in view of anthropologic study of 19-year old males. Wrocław: Monografie Zakładu Antropologii PAN, 23. [in Polish]

7. Eurofit. (1988). European Test of Physical Fitness. Rome: Council of Europe, Committee for the Development of Sport.

8. Raczek, J. (1987). Developmental Conditions of Sports Education of Children and Adolescents. Katowice: AWF Katowice. [in Polish]

9. Kozakiewicz, K., Tendera M., Piwoński J., Głuszek J., Wiercińska E., Bielecki W. \& et al. (2005). Socialeconomic factors and their differences in the Polish population. Results of WOBASZ project. Kardiologia Polska 63(6) (supl. 4), S1-S6. [in Polish]

10. Mleczko, E. (1991). The Course and Determinants of Functional Development of Children in Cracow between 7 and 14 Years of Age. Cracow: Wydawnictwo Monograficzne AWF Kraków, 44. [in Polish]

11. Bodzsár, É.B. (1999). Socio-economic factors and body composition. Int. J. Anthropol. 14(1-2), 171-180.

12. Eiben, O.G. \& Mascie-Taylor C.G.N. (2004). Children's growth and socio-economic status in Hungary. Econ. Hum. Biol. 2, 295-320.

13. Rożnowski, J., Cymek L., Drozd M., Jeka S., Czarny W. \& Czaja R. (2003). Influence of some environmental factors on the development of children and youth from rural areas of Pomorze at the end of the 90s and early twenty-first century. Przeglad Naukowy Kultury Fizycznej Uniwersytetu Rzeszowskiego 1-2, 89-107. [in Polish]
14. Datar, A., Sturm R. \& Magnabosco J.L. (2004). Childhood overweight and academic performance. National study of kindergartners and first-graders. Obes. Res. 12, 58-68.

15. Resiak, M. (2005). Parents' education and physical development of 6-7-year-old children in 1994 and 2003. In T. Lisicki \& et al. (Eds.) Healthy lifestyle. Social conditions (pp. 447-452). Gdańsk: AWFiS Gdańsk. [in Polish]

16. Zadarko-Domaradzka, M. \& Tlałka E. (2007). Influence of socioeconomic factors on variation in height and weight of children. Przeglad Medyczny Uniwersytetu Rzeszowskiego 1, 24-29. [in Polish]

17. Westephal, O. (1995). Normal growth and growth disorders in children. A. Odontol. Scand. 53, 174-178.

18. Cernerud, L. (1994). Are there still social inequalities in height and body mass index of Stockholm children? Scand. J. Soc. Med. 22, 161-165.

19. Martinchick, A.N., Baturin A.K., Feoktistova A.I., Zemluianskaia T.A., Azizbekian G.A., Baeva V.S. \& et al. (1997). Monitoring foot consumption and nutritional status of Moscow schoolchildren in 19921994. Antropometric evaluation of nutritional status, effect of social factors on the character and status of nutrition. Voprosy Pitanija 1, 1-9. [in Russian]

20. Bronikowski, M. (1997). Parents' education and motor efficiency of their children. Roczniki Naukowe AWF Poznań 45, 61-73. [in Polish]

21. Szklarska, A. (1998). Social Differences in Physical Fitness of Children and Adolescents in Poland. Wroclaw: Monografie Zakładu Antropologii PAN, 17. [in Polish]

22. Cieśla, E. \& Nowak-Starz G. (2007). Environmental differentiation of morphofunctional development of children and adolescents aged 10-16. Studia Medyczne Akademii Świętokrzyskiej 8, 21-32. [in Polish]

23. Jaworski, J. \& Szopa J. (1998). Genetic and social conditions of selected somatic and motor predispositions of rural population in Żywiecczyzna. Antropomotoryka 18, 15-47. [in Polish]

24. Malina, R.M. (1989). Training for sport and puberty. In Z. Laron \& A. D. Rogol (Eds.), Hormones and sport. New York: Serano Symposia Publications from Raven Press, 55.

Submitted: June 28, 2010

Accepted: December 2, 2010 